\title{
Antropología y Producción Hidropónica: Plantas medicinales en el Valle de Chagüitillo, Sébaco- Matagalpa 2012-2013
}

\author{
Bra. Jossarys Gazo Robles.
}

Facultad de Humanidades y Ciencias Jurídicas. ${ }^{1}$

Recibido: 13 abril de 2013-Aprobado 28 de octubre 2013.

\section{RESUMEN}

El presente estudio denominado Antropología y Producción Hidropónica: Plantas medicinales en el Valle de Chagüitillo, Sébaco- Matagalpa 2012-2013, tiene el propósito de analizar desde un enfoque antropológico la producción de plantas medicinales a través del uso de la hidroponía. En la comunidad de Chagüitillo se producen plantas nativas con características curativas desde la población indígena y desde dos empresas hidropónicas: "Hidropónicas de Nicaragua S.A" y "Herbay Fresh S.A", siendo parámetros de selección como contexto de estudio. La investigación establece los beneficios naturales de cada una de las especies medicinales necesarias para determinar cuál de las especies es la más viable para su producción a través del método hidropónico. Se plantea el uso de la técnica de cultivo hidropónico como alternativa, de conservar el medio ambiente y la creación de huertos hidropónicos como parte de la estrategia del desarrollo sostenible. Se concluye que el conocimiento tradicional, la experiencia y la sabiduría forman la base de la etnobotánica que incide en la aplicación de los saberes con fines utilitarios, dinámicos y relacionales, especialmente en cuanto a la producción de plantas medicinales con base en el método hidropónico. La innovación con estos tipos de prácticas han generado un impacto positivo y ecológicamente amigable del entorno ambiental y en la economía de las/los productoras/es.

Palabras clave: hidroponía, plantas medicinales, conocimiento tradicional, etnoecología y etnobotánica.

\section{INTRODUCCIÓN}

La investigación es resultado de un importante esfuerzo realizado en el periodo de las Prácticas de Familiarización, Especialización I y II, Taller de Investigación I y II (2011-2012). Las plantas medicinales históricamente se han usado para prevenir y combatir casi todo tipo de enfermedades. En los últimos años, se ha manifestado un gran interés por el descubrimiento del valor medicinal de las plantas. La importancia de la investigación radica en enfocar el desarrollo productivo sostenible de la comunidad de Chagüitillo, para reforzar el uso y conservación de las plantas medicinales vistas como un elemento de la sustentabilidad, buscando mejorar la seguridad y soberanía alimentaria de los habitantes. Se plantea el uso de la técnica de cultivo hidropónico como alternativa, para conservar el medio ambiente. Con dicho método innovador se espera que el productor ponga en práctica no solamente las elecciones que le genere resultado inmediato en cuanto al mejoramiento de su ingreso, sino también que tome en cuenta la conservación del medio ambiente.

El objetivo general de esta investigación es: analizar la producción de plantas medicinales hidropónicas como alternativa de conservación del conocimiento tradicional de la población de Chagüitillo, SébacoMatagalpa. Para la elaboración de la investigación fue necesaria la definición de términos conceptuales, para alcanzar los objetivos establecidos. El primer elemento teórico fue Hidroponía la cual se deriva de las palabras griegas Hydro (agua) y Ponnos (labor o trabajo) y significa "trabajo en agua". El término

\footnotetext{
${ }^{1}$ Trabajo dirigido por la maestra Ligia Espinoza Romero
} 
significa cultivar plantas sin tierras, al suministrar con el agua la cantidad mínima de alimento necesario para desarrollar cultivos sanos, y altamente productivos en menores espacios. (Alpizar A. L., 2006, p. 21). Las plantas medicinales, es el segundo elemento teórico que se define como: vegetales que elaboran unos productos llamados principios activos, que son unas sustancias que ejercen una acción beneficiosa sobre el organismo vivo. Su utilidad primordial, a veces específicas, es servir como droga o medicamentos que alivie la enfermedad o restablezca la salud pérdida; es decir que tiende a disminuir o neutralizar el desequilibrio orgánico que es la enfermedad. (Muños, 1996, pág. 32).

Dentro de la teoría antropológica se abordó la Etnobotánica, según Richard Evans Schultes (1990) es el estudio de las sabidurías botánicas tradicionales, así como las técnicas que de ello se derivan hasta integrarlas en su patrimonio cultural. Otro elemento teórico fue etnoecología, pone el acento en la sabiduría de las poblaciones versus los conocimientos científicos. Según Toledo (1980), la sabiduría se basa en la experiencia concreta y en las creencias compartidas por los individuos acerca del mundo circundante y mantenida, y robustecida mediante testimonios. Por otra parte define a los saberes locales como sistemas de conocimiento holísticos, acumulativos, dinámicos y abiertos, que se construyen con base en las experiencias locales trans-generacionales y, por lo tanto, en constante adaptación a las dinámicas tecnológicas y socioeconómicas (Toledo, 2008). A través de las definiciones teóricas anteriores se pueden identificar la importancia ecológica de los saberes tradicionales, a través del conocimiento relacional, utilitario y dinámico, permitiendo distinguir las cosmovisiones indígenas sobre los elementos que permiten los procesos de producción de plantas medicinales.

\section{MATERIALES Y MÉTODOS}

El tipo de investigación que se realizó fue descriptivo y explicativo sometido a un proceso de análisis de cada una de la variables que se manifiestan en diferentes escenarios y se relacionan en determinado momento, con el objeto de estudio, donde se especifican y miden cada una, de acuerdo a lo que se pretende trabajar. Se tomó como población de estudio a todos los pobladores de Chagüitillo. La muestra es no probalística definida en base a criterio de selección, los que ejercen actividades económicas (productores), así como líderes (casta indígena) y las personas que consumen plantas medicinales.

Desde el método cualitativo, se utilizó el método etnográfico, la entrevista, observación directa y la participativa, diario de campo, observación directa y participante. El análisis de los datos cualitativos se apoyó en el análisis de contenido, dando paso lectura y re-lectura de cada entrevista, algunas fueron contrastadas por la observación participante. Seguidamente fueron codificadas y separadas en unidades de significados colectivos y palabras representativas las cuales dieron lugar a los pre-temas. Desde el método cuantitativo se aplicó la escala de Likert y encuestas. El análisis se realizó utilizando el software para el tratamiento de datos y análisis estadístico Microsoft Excel (2006), con la finalidad de realizar ejercicio usando los comandos para el procesamiento de datos con énfasis en la estadística descriptiva.

\section{RESULTADOS}

\section{Desarrollo de la hidroponía en Chagïitillo-Sébaco, Matagalpa.}

En el Valle de Chagüitillo, la hidroponía se desarrolla desde hace siete años, con la implementación de la primera fábrica Hidropónicas de Nicaragua, S.A. que gerenciaba el Señor Manolo Porro. Una empresa nicaragüense e israelita usuaria del régimen de zona franca, Horti-Tech, dedicada a la producción y exportación de chiltoma, la cual es muy aceptada en el mercado estadounidenses, cuyo comprador único y potencial es Matronardi, una empresa con 50 años de experiencia. En el 2010, llega a la comunidad la segunda Zona Franca Hidropónica denominada "Valley FreshHerbs. S.A", cuyo administrador es Lic. Bayardo José Flores Duarte. En esta, se producen para exportación, plantas medicinales, como Cebollín y 
Albahaca a través del método israelitas. La semilla que se utiliza para la producción y son compradas en Granada. Estas empresas han promovido este método de cultivo porque permite cultivar con un reducido consumo de agua y pequeños trabajos físicos, además se puede producir hortalizas frescas, sanas y abundantes, permitiéndoles competir con el mercado internacional.

\section{Plantas medicinales nativas de Chagüitillo}

La producción de las plantas medicinales a través de la hidroponía se realiza identificando las plantas medicinales nativas de Chagüitillo, y así recomendar especies que sirvan como alternativa hacia el productor al diversificar su producción a través del método hidropónico. Según Evelio Palacios, Ing. agrónomo y miembro de la comunidad indígena: "Todo árbol que al quitarle la corteza sea roja, posee características curativas" (Palacios, 2012) Según Juan Palacios, quien fue presidente de la Comunidad indígena, las siguientes plantas medicinales son nativas: dentro de las grandes se encuentra el jiñocuabo, el carao, guapinol, el genízaro. Dentro de las plantas pequeñas están: Pico de Pájaro, Apazote, Llantén, Dormilona, Sábila, Uña de gato y Orégano”. (Palacio 2012)

\begin{tabular}{|c|c|c|}
\hline $\begin{array}{c}\text { Planta } \\
\text { Medicinal }\end{array}$ & Imagen & Propiedad Curativa \\
\hline jiñocuabo & & $\begin{array}{l}\text { La corteza cocida se usa como antipirético, las hojas maceradas en agua } \\
\text { contra el salpullido y como purgante. El agua tibia o caliente de la } \\
\text { corteza cocida con sal es un buen antiespasmódico y sirve también como } \\
\text { desinflamatorio. }\end{array}$ \\
\hline carao & & $\begin{array}{l}\text { Ayuda al sistema respiratorio: contra la fiebre, catarro, tos, tosferina. } \\
\text { Estimula el apetito, calma el dolor de estómago y la diarrea. Combate la } \\
\text { infección urinaria. Ayuda a regular la menstruación. Elimina ronchas, } \\
\text { paño, hongos, salpullidos, herpes, sarampión. Elimina la anemia, purifica } \\
\text { la sangre. }\end{array}$ \\
\hline guapinol & & $\begin{array}{l}\text { El principal uso medicinal que se le da al guapinol, es contra la tos } \\
\text { además de otros trastornos respiratorios como gripe y asma. También es } \\
\text { utilizada en desórdenes de tipo digestivo como disentería, diarrea y } \\
\text { úlcera. En padecimientos renales, cuando hay inflamación de los riñones, } \\
\text { se prepara un cocimiento de esta planta junto con oreja de lobo } \\
\text { (Clusiasp), bramilla, bejuco de tres costillas, ruda, cabello de elote (Zea } \\
\text { mays), bejuco guaco (Aristolochiasp), anona (Annonareticulata), y cola } \\
\text { de caballo; se toma como agua de uso. }\end{array}$ \\
\hline genízaro & & $\begin{array}{l}\text { Quitar dolor de cabeza. Tiene hojas compuestas, bipinnadas de 3-9 pares } \\
\text { de hasta } 1 \mathrm{dm} \text { de largo, de } 2-4 \mathrm{dm} \text { de longitud, raquis piloso, y las flores, } \\
\text { de color rosado, se reúnen en inflorescencias vistosas situadas al final de } \\
\text { las ramitas. Los frutos son legumbres o vainas oscuras de } 8 \text { a } 20 \mathrm{~cm} \text { de } \\
\text { largo. }\end{array}$ \\
\hline $\begin{array}{l}\text { pico de } \\
\text { pájaro }\end{array}$ & & $\begin{array}{l}\text { Fiebre, catarro, tos, tosferina, dolor de garganta, dolor estómago, diarrea, } \\
\text { colitis aguda, cólicos, hígado, ictericia, dolor menstrual, Occidentalis C. } \\
\text { Occidentalis Conjuntivitis, cólicos. La semilla contiene una substancia } \\
\text { que la hace completamente tóxica para el ganado. Quelite de Fraile J. } \\
\text { Gossyplifolia L. Afecciones Renales, cólicos, etc. Las semillas por su } \\
\text { contenido de Curcinaes bien tóxica. Los síntomas de intoxicación son } \\
\text { quemaduras, vasca, diarrea, cólicos. Contra problemas renales. }\end{array}$ \\
\hline apazote & & $\begin{array}{l}\text { Sirve para el sistema digestivo (parte aérea): dolor de estómago, } \\
\text { indigestión, diarrea, parásitos, lombrices, amebas. Además sirve para la } \\
\text { piel: hongos, llagas, ulceras cutáneas, pajuelillas. }\end{array}$ \\
\hline higuera & & $\begin{array}{l}\text { Sirve para las parótidas, dolor de oído, neuropatía, asma, estreñimiento, } \\
\text { traumatismo, torceduras, reumatismo, quemadura, afección ganglionar, } \\
\text { dolor de cabeza, dolor de muela, y es veneno para rata. }\end{array}$ \\
\hline
\end{tabular}




\begin{tabular}{|c|c|l|}
\hline llantén & $\begin{array}{l}\text { Ayuda contra la faringitis, laringitis, amigdalitis, hígado, diarrea } \\
\text { infecciosa, gastritis, ulcera gástrica, cólicos, chistata, infección renal, } \\
\text { dolor menstrual, inflamación, ulcera llaga y acné }\end{array}$ \\
\hline sábila & $\begin{array}{l}\text { M. Púdica L. Parásitos, inflamaciones Diarrea, Vómito, etc. Su principal } \\
\text { substancia activa, es un la Curcina, un alcaloide que causa desde } \\
\text { debilidad ceguera. Se recomienda sólo en adultos. }\end{array}$ \\
\hline uña de gato & $\begin{array}{l}\text { Para la asma, indigestión, gastritis, ulceras digestivas, estreñimiento, } \\
\text { hígado, mal orín, hemorroides, inflamación, alergia, erisipela, caída del } \\
\text { cabello, ulceras varicosas, repelente contra insectos, ayuda con las } \\
\text { quemaduras leves. }\end{array}$ \\
\hline orégano & $\begin{array}{l}\text { Se usan tradicionalmente el ladrido interno y la raíz para hacer un té. } \\
\text { Trata las enfermedades inflamatorias como la artritis, para limpiar el } \\
\text { tracto digestivo y para tratar el cáncer. También se ha usado para tratar la } \\
\text { disentería, la recuperación del parto, y los desequilibrios de la hormona } \\
\text { de mujeres. Normaliza algunas funciones del sistema inmune. }\end{array}$ \\
\hline & $\begin{array}{l}\text { C. Amboinicus L. graveolens Indigestión, tos Bronquitis, etc. Debido a } \\
\text { su contenido de Alcanfor, en cantidades grandes, puede causar } \\
\text { trastornos. }\end{array}$ \\
\hline
\end{tabular}

\section{Producción de plantas medicinales e hidroponía}

Los métodos para sembrar a través del método hidropónico son dos: a gran escala y de forma artesanal. La primera, con lleva a grandes tecnologías, es llevada a cabo por las empresas de hidroponía mencionadas anteriormente, quienes usan sustratos de alta calidad, usos de invernaderos, proceso de selección y conservación del cultivo y es con fines comerciales, exportación. La segunda forma artesanal, es llevada a cabo por la población indígena consiste en cultivar en cualquier espacio vacío de la casa utilizando elementos reciclables si se desea, su fin es de autoconsumo. La mayoría de las personas no cultivan a través del método hidropónico, porque desconocen de la técnica artesanal debido a que habitan en comunidades rurales. Quienes poseen huertos a base del método hidropónico son aquellas que han trabajo o tiene algún familiar en las empresas Hidropónicas. Por otra parte, para los pobladores de la zona la hidroponía ha venido a beneficiar a la comunidad, no solo en el aspecto ambiental, no dañar la tierra, ahorrar agua en la cosecha, sino que además ha generado más empleos y ha mejorado la calidad de la alimentación familiar, sin aumentar los costos, han fortalecido la economía familiar, disminuyendo los costos de la canasta básica de alimentos. En el siguiente gráfico $\mathrm{N}^{\circ} 1$ se presenta la factibilidad de la hidroponía según los encuestados y entrevistados.

Del $100 \%$ de los encuestados el $65 \%$ afirma estar muy de acuerdo y otro $12 \%$ de acuerdo con que la hidroponía es más factible que el método de cultivo tradicional, haciendo un total de $77 \%$. El 23\% restante se divide en un $17 \%$ que no está ni de acuerdo ni en desacuerdo y otro $6 \%$ que está en desacuerdo, afirmando que es más factible para la producción de plantas medicinales el método tradicional. Las personas que no utilizan este método en la comunidad plantean diferentes razones: no tienen pertinencia en el tema, falta de suficiente dinero para instalar el sistema de cultivo hidropónico, poco conocimiento de las plantas medicinales que si se pueden producir a través de la hidroponía, desconocimiento de la forma barata de crear su huerto.

Ante esta problemática, se plantea una breve explicación de la forma sencilla para imprentar un huerto hidropónico y producir plantas medicinales. Se delimita el espacio, es posible cultivar en menos de un metro cuadrado en patios caseros que se pueden tener en una vivienda. Los Recipientes tan pequeños como los envases plásticos para helados, los vasos plásticos desechables son suficientes para cultivar acelgas, cebollas, lechugas, perejil y otras hortalizas. Estos tipos de recipientes y contenedores que se pueden construir deben estar de acuerdo con el espacio disponible, las posibilidades técnicas y económicas, y las necesidades y aspiraciones de progreso y desarrollo del grupo familiar. Estos se 
caracterizan porque las dimensiones (largo y ancho) de los contenedores pueden ser muy variables, pero su profundidad no debe ser mayor de $10-12 \mathrm{~cm}$. Otro elemento necesario para la producción son los sustratos o medios de cultivo, estos deben tener gran resistencia al desgaste o a la meteorización y es preferible que no tengan sustancias minerales solubles para no alterar el balance químico de la solución nutritiva que será aplicada. El material no debería ser portador de ninguna forma viva de macro o microorganismo, para disminuir el riesgo de propagar enfermedades o causar daño a las plantas, a las personas o a los animales que las van a consumir.

\section{DISCUSIÓN}

El conocimiento utilitario y conocimiento tradicional que la población posee sobre las plantas medicinales se caracteriza desde la cultura material e inmaterial. La cultura material, porque se utilizan diversas partes de las plantas como madera por ejemplo, y cultura inmaterial, porque se utilizan para remedios, para curar diversos males, apartar espíritus, se les asigna poder, curación, fe y simbolismo. En la población de Chagüitillo se identifica que los saberes locales son sistemas de conocimiento holísticos, acumulativos, dinámicos y abiertos, que se construyen con base en las experiencias locales trans-generacionales y, por lo tanto, en constante adaptación a las dinámicas tecnológicas y socioeconómicas; esa sabiduría se demuestra, en el que se demuestra en la cultura.

Las plantas medicinales de Chagüitillo al ser identificadas y percibidas como recursos materiales, permite identificar en la población un conocimiento utilitario, con ello se adapta una visión que restringe la idea de lo utilitario a lo meramente material. Según Meza, las plantas medicinales aparte de tener un valor curativo en la medicina tradicional, también tiene un valor cultural y comercial. En el caso medicinal la constitución de Nicaragua ha promovido el aprovechamiento de la medicina tradicional, para asegurar el acceso efectivo a los servicios de salud de las comunidades indígenas.

\section{CONCLUSIONES}

El conocimiento tradicional, la experiencia y la sabiduría forman la base de la etnobotánica que incide en la aplicación de los saberes con fines utilitarios, dinámicos y relacionales, especialmente en cuanto a la producción de plantas medicinales con base en el método hidropónico esta innovación ha generado un impacto positivo y ecológicamente amigable del entorno ambiental y en la economía de las/los productoras/es.

Las especies de plantas medicinales que la población podría cultivar a través del método hidropónico: Culantro Albahaca Chaya (chayote) Apazote, Hierbabuena, Remolacha, Sábila, Lechuga, Ajo, Ruda, Orégano, espinaca, Jengibre, Manzanilla, Apio, Zanahoria, Pepino, Tomate, Rábano y Zacate de Limo,

\section{BIBLIOGRAFÍA}

Blanco. (2008). Tejo y cultura: de la tradición etnobotánica a la farmacología científica.

Chagutillo, E. y. (s.f.). Chagüitillo, Sébaco-Matagalpa, Nicaragua.

Muños, F. (1996). Plantas medicinales y Aromáticas. México.

Pérez, J. (16 de abril de 2012). Alcalde Municipal. (Jossarys..., Entrevistador)

Schultes, r. e. (1990). Etnobotánica. Córdoba.

Toledo, V. M. (1991). El juego de la Supervivencia. Chile: CLADES.

Toledo, V. M. (2008). Memoria Biocultural. . ICARIA. 